\title{
I'll Go to the Library Later: The Relationship between Academic Procrastination and Library Anxiety
}

\author{
Anthony J. Onwuegbuzie and Qun G. Jiao
}

\begin{abstract}
Approximately 95 percent of college students procrastinate on academic tasks such as writing term papers, studying for examinations, and keeping up with weekly reading assignments. At the graduate level, an estimated 60 percent of students procrastinate on academic tasks. Academic procrastination stems primarily from fear of failure and task aversiveness. It has been theorized, though not tested empirically, that highly anxious graduate students typically procrastinate while engaged in library-related tasks. This study investigated the relationship between academic procrastination and library anxiety at the graduate level. Participants included 135 graduate students enrolled in three sections of a required introductory-level educational research course. Findings revealed that, overall, academic procrastination was significantly positively related to the following dimensions of library anxiety: affective barriers, comfort with the library, and mechanical barriers. A canonical correlation analysis revealed that academic procrastination resulting from both fear of failure and task aversiveness was related significantly to barriers with staff, affective barriers, comfort with the library, and knowledge of the library. Implications for library anxiety reduction as a procrastination intervention are discussed.
\end{abstract}

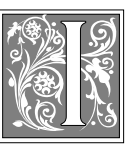

$\mathrm{t}$ is estimated that approximately 95 percent of college students engage in frequent academic procrastination, the purposive delay in beginning or completing academic tasks. ${ }^{1-2}$ Academic procrastination has been found to be prevalent among both undergraduate and graduate students, across racial categories, and between genders. ${ }^{3-6}$ Studies indicate that the tasks that induce academic procrastination include writing term papers, study- ing for examinations, and keeping up with weekly reading assignments. ${ }^{7}$ Academic procrastination also is associated with missing deadlines for submitting assignments, delaying the taking of selfpaced quizzes, claiming test anxiety, receiving low course grades, and attaining low cumulative grade point averages. ${ }^{8-12}$

Laura J. Solomon and Esther D. Rothblum found that between 27 and 46 percent of undergraduate students reported that they always or almost always

Anthony J. Onwuegbuzie is an Assistant Professor in the Department of Educational Leadership, College of Education, at Valdosta State University; e-mail: tonwuegb@valdosta.edu. Qun G. Jiao is an Associate Professor and Reference Librarian in Newman Library, Baruch College, at the City University of New York; e-mail: qunbb@cunyom.cuny.edu. 
procrastinated on writing term papers, studying for examinations, and keeping up with weekly readings. The authors also discovered that nearly one-quarter of these students reported that procrastination was always or almost always a problem for them when undertaking these tasks. ${ }^{13}$

Similarly, Jeffrey L. Clark and Oliver W. Hill found that between 30 and 45 percent of African-American undergraduate students reported problems with procrastination on writing term papers, studying for examinations, and keeping up with weekly reading assignments. Moreover, between 55 and 60 percent of the students wanted to decrease their procrastination on these tasks. ${ }^{14}$

\section{The study participants consisted of 135 graduate students enrolled in several sections of a graduate-level research methodology course at a small midsouthern university.}

Using factor analysis, Solomon and Rothblum found that fear of failure and task aversiveness are the primary reasons for procrastinating, with the former explaining 49 percent of the variance in why undergraduate students procrastinate and the latter accounting for 18 percent of the variance. The fear of failure factor includes items that relate to evaluation anxiety and overly perfectionistic standards for one's performance and low self-confidence. In contrast, the task aversiveness factor comprises items that reflect a dislike of engaging in academic activities and a lack of energy. The authors reported that the percentage of college students who endorsed items representing the fear of failure factor ranged from 6.3 to 14.1 percent, whereas endorsement of the task aversiveness factor ranged from 19.4 to 47.0 percent. These findings led the authors to conclude that procrastinators at the undergraduate level could be divided into two groups: a relatively small, but extremely homogenous, group of students who procrastinate because of fear of failure; and a relatively heterogeneous group of students who procrastinate because of task aversiveness. ${ }^{15}$
Recently, Anthony J. Onwuegbuzie found that 41.7 percent of graduate students reported that they always or almost always procrastinate on writing a term paper, 39.3 percent procrastinate on studying for examinations, and 60.0 percent procrastinate on keeping up with weekly reading assignments. In addition, between 21 and 42 percent reported that procrastination was always or almost always a problem when undertaking these tasks, and between 65 and 72 percent wanted to decrease their tendency to procrastinate. ${ }^{16}$

Surprisingly, graduate students may have an even greater tendency to procrastinate on academic tasks than do undergraduate students. Indeed, Onwuegbuzie found that graduate students were nearly 3.5 times more likely to report that they always or almost always procrastinate on keeping up with weekly reading assignments and nearly 2.5 times more likely to report that procrastination was always or almost always a problem when studying for examinations than were a comparison group of undergraduate students in Solomon and Rothblum's study. ${ }^{17,18}$

Although the effects of academic procrastination among graduate students can influence performance in all academic areas, it is likely that it is particularly detrimental when students are engaged in proposing and/or conducting research, as is typically the case in research methodology courses. Onwuegbuzie found that many graduate students procrastinate at various stages of the research process, including while engaged in the literature review process. ${ }^{19}$ Because many students also experience library anxiety while conducting research, it is likely that academic procrastination is related to library anxiety, although this has not been tested empirically. ${ }^{20}$

Constance A. Mellon described library anxiety as a situation-specific, negative feeling or emotional disposition that occurs when a student is in a library setting. ${ }^{21} \mathrm{It}$ also has been reported that library anxiety de-motivates students from beginning or prolonging their search, thereby impeding development of their library skills. ${ }^{22-24}$ According to CarolC. Kuhlthau, students with 
high levels of library anxiety tend to engage in negative ruminations that lead to cognitive interference during various stages of the information search process. Kuhlthau identified six stages during which anxiety levels may be elevated: task initiation, topic selection, prefocus exploration, focus formulation, information collection, and search closure. ${ }^{25,26}$ Onwuegbuzie reported that many graduate students constantly expressed their discomfort with the library search process, suggesting that they experience difficulties adapting to the library environment. ${ }^{27}$

According to Rothblum, Soloman, and Janice Murakami, academic procrastinators have the self-reported tendency to always or almost always experience problematic levels of anxiety. ${ }^{28}$ Moreover, academic procrastination has been found to be related positively to generalized and specific kinds of anxiety such as test anxiety, social anxiety, and statistics anxiety. ${ }^{29-}$ ${ }^{31}$ Thus, the purpose of this study was to investigate the relationship between academic procrastination and library anxiety. Specifically, the relationships between academic procrastination and five library anxiety dimensions were studied empirically. It was hypothesized that academic procrastination would be positively related to library anxiety.

\section{Method}

\section{Participants}

The study participants consisted of 135 graduate students enrolled in several sections of a graduate-level research methodology course at a small midsouthern university. Participation in the study was voluntary and anonymous, with no student declining. To participate, students were required to sign informed consent documents. The ages of the participants ranged from twenty-one to fifty-one (mean $=26.0, S D=6.8$ ). Mean academic achievement, as measured by grade point average, was $3.57(S D=0.36)$. The overwhelming majority of the participants were female (92.6 percent) and white ( $93.3 \%)$. However, a nonparametric Wilcoxon two-sample $t$ test revealed no gender difference $(p<.05)$ with respect to levels of overall academic procrastination, fear of failure, and task aversiveness. ${ }^{32}$ Indeed, this finding is consistent with other studies in which procrastination scores by males and females were not significantly different. ${ }^{33-36}$ In addition, a series of Wilcoxon two-sample $t$-tests revealed no gender difference $(p<.05)$ with respect to the five dimensions of library anxiety. Thus, all data were collapsed across gender.

\section{Instruments and Procedure}

Participants were administered the Library Anxiety Scale (LAS) and the Procrastination AssessmentScale-Students (PASS). Developed by Sharon L. Bostick, the LAS is a 43item, 5-point Likert-format instrument that assesses levels of library anxiety. ${ }^{37}$ The instrument has five subscales: barriers with staff, affective barriers, comfort with the library, knowledge of the library, and mechanical barriers. "Barriers with staff" refers to the perceptions of students that librarians and other library staff are intimidating, unapproachable, and too busy to provide assistance in using the library. "Affective barriers" stems from students' feelings of inadequacy about using the library. "Comfort with the library" deals with how safe, welcoming, and nonthreatening students perceive the library to be. "Knowledge of the library" refers to how familiar students feel they are with the library. Finally, "mechanical barriers" refers to feelings that emerge as a result of student reliance on mechanical library equipment, including computer printers, copy machines, and change machines. A high score on any subscale represents high anxiety in this area. Qun G. Jiao and Anthony J. Onwuegbuzie found that the LAS subscales generated scores that yielded coefficient alpha reliabilities ranging from .60 (mechanical barriers) to .90 (barriers with staff). ${ }^{38}$ For the present study, scores from the subscales yielded alpha reliability coefficients ranging from .65 (knowledge of the library) to .94 (barriers with staff).

The PASS, which was developed by Solomon and Rothblum, consists of two parts. ${ }^{39}$ The first part lists six academic 
tasks involving writing a term paper, studying for examinations, keeping up with weekly reading assignments, performing administrative tasks, attending meetings, and performing academic tasks in general. Respondents are asked to complete three rating scales for the six tasks indicating the frequency with which they procrastinate on each task $(1=$ Never procrastinate; 5 = Always procrastinate), whether their procrastination on the task is a problem $(1=$ Not at all a problem; $5=$ Always a problem), and whether they want to decrease their procrastination on the task ( $1=$ Do not want to decrease; $5=$ Definitely want to decrease). As recommended by Solomon and Rothblum, the PASS items pertaining to the frequency with which respondents procrastinate on a task and whether their procrastination is a problem were summed to provide an overall measure of academic procrastination, with total scores ranging from twelve to sixty. Higher scores are indicative of selfreported academic procrastination. ${ }^{40}$

The second section of the PASS asks students to think of the last time they procrastinated on writing a term paper. Students then indicated how much each of the twenty-six reasons reflected why they procrastinated $(1=$ Not at all reflects why I procrastinated; $5=$ Definitely reflects why I procrastinated). A factor analysis undertaken by Solomon and Rothblum on the reasons why college students procrastinate indicated two factors: fear of failure and task aversiveness. ${ }^{41}$

The PASS has been shown to possess adequate construct validity, as evidenced by significant relationships between scores on the scale and behavioral measures of procrastination such as delay in taking selfpaced quizzes and in handing in a term paper, delay in submitting course requirements, and delay in participating in psychology experiments. ${ }^{42-44}$ Furthermore, Joseph R. Ferrari reported adequate internal consistency estimates for each part of the PASS and both factors ranging from .60 to .80 , and acceptable test-retest reliabilities at one month ranging from .63 to $.74 .{ }^{45}$ For the present study, the coefficient alpha re- liability estimates of the PASS measures were .84 for the procrastination scale, .85 for the fear of failure factor, and .76 for the task aversiveness factor.

\section{Data Analysis}

A canonical correlation analysis was conducted to identify a combination of reasons for procrastination dimensions (namely, fear of failure and task aversiveness) that might be correlated with a combination of library anxiety dimensions. Canonical correlation analysis is utilized to examine the relationship between two sets of variables when each set contains more than one variable. ${ }^{46-49}$ Indeed, as noted by Thomas R. Knapp, "virtually all of the commonly encountered tests of significance can be treated as special cases of canonical correlation analysis." ${ }^{50}$ That is, canonical correlation analysis can be used to undertake all the parametric tests that canonical correlation methods subsume as special cases, including $t$-tests, multiple regression, analysis of variance, and analysis of covariance. ${ }^{51}$

In the present study, the five dimensions of library anxiety were treated as the dependent multivariate set of variables, whereas the two components of reasons for procrastination were utilized as the independent multivariate set of variables. The number of canonical functions (i.e., factors) that can be generated for a given data set is equal to the number of variables in the smaller of the two variable sets. Because the reason for procrastination section of the PASS has two dimensions and the LAS has five dimensions, two canonical functions were generated.

For the first canonical coefficient, standardized canonical function coefficients and structure coefficients were computed. Standardized canonical function coefficients are computed weights that are applied to each variable in a given set in order to obtain the composite variate used in the canonical correlation analysis. As such, standardized canonical function coefficients are analogous to factor pattern coefficients in factor analysis or to beta coefficients in a regression analysis. ${ }^{52}$ Struc- 
ture coefficients are the correlations between a given variable and the scores on the canonical composite (namely, the latent variable) in the set to which the variable belongs. ${ }^{53}$ Thus, structure coefficients indicate the extent to which each variable is related to the canonical composite for the variable set. Indeed, structure coefficients are essentially bivariate correlation coefficients that range in value between 1.0 and +1.0 inclusive. ${ }^{54}$ The square of the structure coefficient is the proportion of variance that the original variable shares linearly with the canonical variate.

\section{Results}

Table 1 presents the Pearson product-moment correlations (zero-order correlations) between overall academic procrastination and the five dimensions of library anxiety. Using the Bonferroni adjustment to control for type I error, it can be seen that overall academic procrastination was related positively to affective barriers, comfort with the library, and mechanical barriers.

Table 1 also presents the correlations between the two reasons for procrastination subscales (fear of failure and task aversiveness) and the five dimensions of library anxiety. Again, using the Bonferroni adjustment, it can be seen that (1) fear of failure was related positively to affective barriers and comfort with the library and (2) task aversiveness was related positively to affective barriers and knowledge of the library.

The strength of the relationship between the two sets of variables was assessed by examining the magnitude of the canonical correlation coefficients. These coefficients indicate the degree of relationship between the weighted procrastination variables and the weighted library anxiety variables. In addition, the significance of the canonical roots was tested via the F-statistic based on Radhakrishna C. Rao's approximation. ${ }^{55}$

The canonical analysis revealed that both canonical correlations combined were statistically significant $(F[10,256]=$ $3.45, p<.05)$. However, when the first canonical root was excluded, the remaining canonical root was not statistically significant, suggesting that the first canonical function was statistically significant, but the second canonical root was not statistically significant. However, because the calculated probabilities are sensitive to sample size, particular attention should be paid to the educational (practical) significance of the obtained results. ${ }^{56}$ The educational significance of canonical correlations typically are assessed by examining their size. The canonical correlation indicates how much variance the sets of weighted original variables share with each other. ${ }^{57-60}$ In the present study, the first canonical correlation $\left(\mathrm{R}_{\mathrm{c} 1}=.42\right)$

TABLE 1

Pearson Product-Moment Correlations of Procrastination Measures and the Library Anxiety Dimensions

\begin{tabular}{|c|c|c|c|}
\hline \multirow[b]{2}{*}{$\begin{array}{l}\text { Library } \\
\text { Anxiety } \\
\text { Dimensions }\end{array}$} & \multicolumn{3}{|c|}{ Procrastination Measures } \\
\hline & $\begin{array}{c}\text { Academic } \\
\text { Procrastination }\end{array}$ & $\begin{array}{l}\text { Fear of } \\
\text { Failure }\end{array}$ & $\begin{array}{c}\text { Task } \\
\text { Aversiveness }\end{array}$ \\
\hline Barriers with staff & .19 & .20 & .03 \\
\hline Affective barriers & $.24^{*}$ & $.39^{*}$ & $.22^{*}$ \\
\hline Comfort with the library & $.25^{*}$ & $.23^{*}$ & .10 \\
\hline Knowledge of the library & .09 & .16 & $.22^{*}$ \\
\hline Mechanical barriers & $.24^{*}$ & .09 & .04 \\
\hline
\end{tabular}


TABLE 2

Canonical Solution for First Function

\begin{tabular}{lccc}
\hline \hline Measure & $\begin{array}{c}\text { Standardized } \\
\text { Coefficient }\end{array}$ & $\begin{array}{c}\text { Structure } \\
\text { Coefficient }\end{array}$ & $\begin{array}{c}\text { Structure } \\
\text { (\%) }\end{array}$ \\
\hline Library Anxiety Dimension: & & & \\
Barriers with staff & $-0.305^{*}$ & $.411^{*}$ & 16.9 \\
Affective barriers & $1.122^{*}$ & $.938^{*}$ & 88.0 \\
Comfort with the library & -0.044 & $.533^{*}$ & 28.4 \\
Knowledge of the library & 0.261 & $.503^{*}$ & 25.3 \\
Mechanical barriers & -0.165 & .215 & 4.6 \\
& & & \\
Reason for Procrastination Dimension: & & & \\
Fear of failure & $0.792^{*}$ & $.933^{*}$ & 87.0 \\
Task aversiveness & $0.387^{*}$ & $.675^{*}$ & 45.6 \\
& & & \\
"Loadings with large-effect sizes & & &
\end{tabular}

appeared to be moderately educationally significant, contributing 17.6 percent $\left(\mathrm{R}_{\mathrm{c} 1}{ }^{2}\right)$ to the shared variance. However, the second canonical correlation $\left(\mathrm{R}_{\mathrm{c} 2}{ }^{2}=.06\right) \mathrm{did}$ not appear to be educationally significant. Consequently, only the first canonical correlation was interpreted.

Data pertaining to the first canonical root are presented in table 2 . Table 2 provides both standardized function coefficients and structure coefficients. Examination of the standardized canonical function coefficients revealed that, using a cutoff correlation of 0.3 recommended by Zarrel V. Lambert and Richard M. Durand as an acceptable minimum loading value, two of the five library anxiety dimensions (barriers with staff and affective barriers) made an important contribution to the anxiety composite, with affective barriers being the major contributor. ${ }^{61}$

With respect to the reasons of procrastination set, both dimensions (fear of failure and task aversiveness) made an important contribution to the composite set. However, although the absolute magnitude of the standardized function coefficients may be relatively reliable in ascertaining the contribution of a variable to the composite, the numerical values of these coefficients are highly affected by the collinearity of the variables in a given set. ${ }^{62}$ Due to the moderate to large statistically significant intercorrelations among the two reasons for procrastination factors $(r=.36)$ and the library dimensions (the intercorrelations ranged from .26 to .79), the structure coefficients represented the primary statistics that were interpreted.

The structure coefficients (table 2) revealed that four of the five dimensions of library anxiety made important contributions to the first canonical variate. The square of the structure coefficient (table 2) indicated that affective barriers made an extremely large contribution, explaining 88 percent of the variance. Barriers with staff, comfort with the library, and knowledge of the library made moderate contributions, explaining 16.9 percent, 28.4 percent, and 25.3 percent of the variance, respectively. With regard to the reasons for procrastination cluster, both dimensions made noteworthy contributions, with fear of failure explaining 87 percent of the variance and task aversiveness 45.6 percent.

\section{Discussion}

The purpose of this study was to investigate empirically the relationship between academic procrastination and five dimensions of library anxiety. Findings revealed that, overall, academic procrastination is significantly positively related to affective barriers, comfort with the library, and mechanical barriers. In addition, academic 
procrastination resulting from both fear of failure and task aversiveness appears to be related significantly to barriers with staff, affective barriers, comfort with the library, and knowledge of the library. These findings are consistent with those of Onwuegbuzie, who noted that many graduate students procrastinate while engaged in the process of writing a research proposal..$^{63}$ These results are also in accordance with the bulk of the literature that has documented a relationship between academic procrastination and the generalized and specific kinds of anxiety such as test anxiety, statistics anxiety, social anxiety, and self-consciousness. ${ }^{64-68}$

\section{Although there is strong evidence of a relationship between academic procrastination and library anxiety, it is unclear whether it is a causal relationship.}

The relationship between academic procrastination and library anxiety provides further evidence that procrastination is more than deficits in time management and study skills but also includes cognitive-affective components. ${ }^{69,70}$ In fact, according to Rothblum, Solomon, and Murakami, high procrastinators do not differ in their study behavior as much as they do on anxiety. ${ }^{71}$

Although there is strong evidence of a relationship between academic procrastination and library anxiety, it is unclear whether it is a causal relationship. That is, it is unclear whether academic procrastination is a cause of library anxiety or whether library anxiety promotes academic procrastination. Perhaps it is most likely that a bidirectional relationship exists between academic procrastination and library anxiety, with each affecting the other. If this is true, it would indicate that academic procrastination and library anxiety are intricately intertwined. For example, it is possible that while engaged in the research process, high-procrastinating graduate students experience extreme elevations in library anxiety. Individuals who experience increases in levels of li- brary anxiety are more likely to postpone using the library and performing library tasks. In any case, this cycle of procrastination and library anxiety is likely to continue until levels of both are maximized. Where for some students the procrastination component of the cycle is likely to stem from a fear of failure, for others the driving force is task aversiveness.

Several studies have indicated that some academic procrastinators engage in perfectionism in an effort to either produce a flawless product (those with a tendency of selfperfectionism) or impress others by their efforts (those with a tendency of socially prescribed perfectionism). ${ }^{72-75}$ In addition, a relationship between perfectionism and library anxiety has been reported by Jiao and Onwuegbuzie. ${ }^{76}$ These findings, together with the findings from the current study, suggest that either the relationship between academic procrastination and library anxiety is moderated by levels of perfectionism or the relationship between perfectionism and library anxiety is moderated by levels of academic procrastination. In any case, future research should investigate the interplay between procrastination, perfectionism, and library anxiety.

The fact that no gender differences were found in the present study with respect to overall academic procrastination, fear of failure, task aversiveness, and all five dimensions of library anxiety and the fact that the overwhelming majority of previous research has documented that males and females report similar levels of academic procrastination suggest that the findings of the present study may be similarly generalizable to both male and female graduate students. ${ }^{77-80}$ However, male students have been found to report higher levels of library anxiety than female students. ${ }^{81}$ Thus, it is unclear how generalizable the findings of the present study are across gender. If, indeed, males do experience higher levels of library anxiety than do females, it is possible that the relationship between academic procrastination and library anxiety found in this study would have been even stronger if more males had been included in the sample. 
The fact that academic procrastination was assessed via a self-report instrument, rather than based on actual behavior, is perhaps another limitation of the study because it is possible that students may give socially desirable responses. However, according to Rothblum, Solomon, and Murakami, selfreported procrastination has been validated against delay in taking self-paced quizzes, delay in submitting course assignments, delay in participation in psychology experiments, and lower course grades. ${ }^{82,83}$ Notwithstanding, future studies in this area should consider using behavioral measures of academic procrastination in addition to self-report instruments. In particular, qualitative studies are needed that investigate the role of academic procrastination through each of Kuhlthau's six stages of the information search process because students are likely to procrastinate at one or more of these stages. ${ }^{84,85}$ Moreover, future research should determine the stage at which procrastination is most prevalent and debilitative.

\section{Conclusion}

To the extent that the findings of the present study are replicable, several practical implications can be derived. Perhaps most importantly, the results suggest that whereas some graduate students may benefit from traditional interventions for procrastination such as time management and study skills, self-discipline and selfcriticism, compliance-based and defiancebased paradoxical strategies, and the use of external contingencies, others may benefit more from interventions that focus on anxiety management and reduction..$^{86-94}$ Academic advisors and librarians should combine their efforts in helping to reduce library anxiety among graduate students by teaching them how to direct attention away from self-centered worries when they are engaged in the library search process. By using such interventions, it is hoped that more graduate students will be positive about using the library, in general, and about the information search process, in particular.

\section{Notes}

1. Albert Ellis and William J. Knaus, Overcoming Procrastination ( New York: Institute for Rational Living, 1977).

2. Mary B. Hill, "A Survey of College Faculty and Student Procrastination," College Student Journal 12, no.2 (fall 1978): 256-62.

3. Laura J. Solomon and Esther D. Rothblum, "Academic Procrastination: Frequency and Cognitive-Behavioral Correlates," Journal of Counseling Psychology 31 (Oct. 1984): 503-9.

4. Anthony J. Onwuegbuzie, "Academic Procrastination and Statistics Anxiety." Article submitted for publication, (1999).

5. Joseph R. Ferrari, Johnson L. Judith, and William G. McCown, Procrastination and Task Avoidance: Theory, Research, and Treatment (New York: Plenum Publications, 1995).

6. Ibid.

7. Solomon and Rothblum, "Academic Procrastination."

8. Gery Beswick, Esther D. Rothblum, and Leon L. Mann, "Psychological Antecedents of Student Procrastination," Australian Psychologist 23, no. 2 (July 1988): 207-17.

9. Jeffrey L. Clark and Oliver W. Hill, "Academic Procrastination among African-American College Students," Psychological Reports 75, no.2 (Oct. 1994): 931-36.

10. Clarry H. Lay and Stuart Silverman, "Trait Procrastination, Anxiety, and Dilatory Behavior," Personality and Individual Differences 21, no. 1 (July 1996): 61-67.

11. Esther D. Rothblum, Laura J. Solomon, and Janice Murakami, "Affective, Cognitive, and Behavioral Differences between High and Low Procrastinators," Journal of Counseling Psychology 33 (Oct. 1986): 387-94.

12. Raymond N. Wolfe and Scott D. Johnson, "Personality as a Predictor of College Performance," Educational and Psychological Measurement 55, no. 2 (Apr. 1995): 177-85.

13. Solomon and Rothblum, "Academic Procrastination."

14. Clark and Hill, "Academic Procrastination among African-American College Students."

15. Solomon and Rothblum, "Academic Procrastination."

16. Onwuegbuzie, "Academic Procrastination and Statistics Anxiety."

17. Ibid.

18. Solomon and Rothblum, "Academic Procrastination." 
19. Onwuegbuzie, "Academic Procrastination and Statistics Anxiety."

20. Ibid.

21. Constance A. Mellon, "Library Anxiety: A Grounded Theory and Its Development," College $\mathcal{E}$ Research Libraries 47 (Mar. 1986): 160-65.

22. — "Attitudes: The Forgotten Dimension in Library Instruction," Library Journal 113 (Sept. 1, 1988): 137-39.

23. Carol C. Kuhlthau, "Developing a Model of the Library Search Process: Cognitive and Affective Aspects," RQ 28 (winter 1988): 232-42.

24. _ "Inside the Search Process: Information Seeking from the User's Perspective," Journal of the American Society for Information Science 42 (June 1991): 361-71.

25. Kuhlthau, "Developing a Model of the Library Search Process."

26. —— "Inside the Search Process."

27. Onwuegbuzie, "Academic Procrastination and Statistics Anxiety."

28. Rothblum, Solomon, and Murakami, "Affective, Cognitive, and Behavioral Differences between High and Low Procrastinators."

29. Onwuegbuzie, "Academic Procrastination and Statistics."

30. Rothblum, Solomon, and Murakami, "Affective, Cognitive, and Behavioral Differences between High and Low Procrastinators."

31. Solomon and Rothblum, "Academic Procrastination."

32. Myles Hollander and Douglas A.Wolfe, Nonparametric Statistical Methods (New York: John Wiley, 1973).

33. Barbara R. Effert and Joseph R. Ferrari, “Decisional Procrastination: Examining Personality Correlates," Journal of Social Behavior and Personality 4, no. 1 (1989): 151-61.

34. Joseph R. Ferrari, "Reliability of Academic and Dispositional Measures of Procrastination," Psychological Reports 64 (June 1989): 1057-58.

35. —_ "A Preference for a Favorable Public Impression by Procrastinators: Selecting among Cognitive and Social Tasks," Personality and Individual Differences 12, no. 11 (1991): 1233-37.

36. —_ "Procrastinators and Project Creation: Choosing Easy, Nondiagnostic Items to Avoid Self-Relevant Information," Journal of Social Behavior and Personality 6, no. 3 (Sept. 1991): 619-28.

37. Sharon L. Bostick, "The Development and Validation of the Library Anxiety Scale" (Ph.D. diss., Wayne State Univ., 1992).

38. Qun G. Jiao and Anthony J. Onwuegbuzie, "Antecedents of Library Anxiety," Library Quarterly 67, no. 4 (Oct. 1997): 372-89.

39. Solomon and Rothblum, "Academic Procrastination."

40. Ibid.

41. Ibid.

42. Ibid.

43. Beswick, Rothblum, and Mann, "Psychological Antecedents of Student Procrastination."

44. Solomon and Rothblum, "Academic Procrastination."

45. Ferrari, "Reliability of Academic and Dispositional Measures of Procrastination."

46. Norman Cliff and David J. Krus, "Interpretation of Canonical Analyses: Rotated vs. Unrotated Solutions," Psychometrica 41 (Mar. 1976): 35-42.

47. Richard B. Darlington and Sharon Weinberg, "Canonical Variate Analysis and Related Techniques," Review of Educational Research 43 (fall 1973): 433-54.

48. Bruce Thompson, "Canonical Correlation: Recent Extensions for Modelling Educational Processes" (paper presented at the annual meeting of the American Educational Research Association, Boston, Apr. 7-11, 1980 [ERIC ED 199 269]). 1984).

49. —- Canonical Correlation Analysis: Uses and Interpretations (Beverly Hills, Calif.: Sage,

50. Thomas R. Knapp, "Canonical Correlation Analysis: A General Significance Parametric Significance-Testing System," Psychological Bulletin 85, no. 2 (Mar. 1978): 410-16.

51. Bruce Thompson, "Canonical Correlation Analysis: An Explanation with Comments on Correct Practice" (paper presented at the annual meeting of the American Educational Research Association, New Orleans, Apr. 1988 [ERIC ED 295 957]).

52. Margery E. Arnold, "The Relationship of Canonical Correlation Analysis to Other Parametric Methods" (paper presented at the annual meeting of the Southwest Educational Research Association, New Orleans, Jan. 1996 [ERIC ED 395 994]).

53. Thompson, "Canonical Correlation."

54. Ibid.

55. Radhakrishna C. Rao, Advanced Statistical Methods in Biometric Research (New York: Wiley, 1952).

56. Thompson, "Canonical Correlation."

57. Ibid.

58. Thompson, Canonical Correlation Analysis. 
59. —_ "Canonical Correlation Analysis."

60. _ _ "Variable Importance in Multiple Regression and Canonical Correlation" (paper presented at the annual meeting of the American Educational Research Association, Boston, Apr. 1990 [ERIC ED 317 615]).

61. Zarrel V. Lambert and Richard M. Durand, "Some Precautions in Using Canonical Analysis," Journal of Market Research 7 (Apr. 1975): 468-75.

62. Thompson, "Variable Importance in Multiple Regression and Canonical Correlation."

63. Anthony J. Onwuegbuzie, "Writing a Research Proposal: The Role of Library Anxiety, Statistics Anxiety, and Composition Anxiety," Library \& Information Science Research 19, no. 1 (1997): 5-33.

64. Joseph R. Ferrari, "Compulsive Procrastination: Some Self-Reported Characteristics," Psychological Reports 68, no. 2 (Apr. 1991): 455-58.

65. Norman A. Milgram, "Procrastination," in Encyclopedia of Human Biology, vol. 6 (New York: Academic Pr., 1991), 149-55.

66. Onwuegbuzie, "Academic Procrastination and Statistics Anxiety."

67. Rothblum, Solomon, and Murakami, "Affective, Cognitive, and Behavioral Differences between High and Low Procrastinators."

68. Solomon and Rothblum, "Academic Procrastination."

69. Rothblum, Solomon, and Murakami, "Affective, Cognitive, and Behavioral Differences between High and Low Procrastinators."

70. Solomon and Rothblum, "Academic Procrastination."

71. Rothblum, Solomon, and Murakami, "Affective, Cognitive, and Behavioral Differences between High and Low Procrastinators."

72. Joseph R. Ferrari, "Procrastinators and Perfect Behavior: An Exploratory Factor Analysis of Self-Presentation, Self-Awareness, and Self-Handicapping Components," Journal of Research in Personality 26 (Mar. 1992): 75-84.

73. Onweugbuzie, "Writing a Research Proposal."

74. Douglas D. Saddler and Laurie A. Sacks, "Multidimensional Perfectionism and Academic Procrastination: Relationships with Depression in University Students," Psychological Reports 73 (Dec. 1993): 863-71.

75. Solomon and Rothblum, "Academic Procrastination."

76. Qun G. Jiao and Anthony J. Onwuegbuzie, "Perfectionism and Library Anxiety among Graduate Students," Journal of Academic Librarianship 24 (Sept. 1998): 365-71.

77. Effert and Ferrari, "Decisional Procrastination."

78. Ferrari, "Reliability of Academic and Dispositional Measures of Procrastination."

79. Ferrari, "A Preference for a Favorable Public Impression by Procrastinators."

80. Ferrari, "Procrastinators and Project Creation."

81. Qun G. Jiao, Anthony J. Onwuegbuzie, and Art A. Lichtenstein, "Library Anxiety: Characteristics of at-Risk College Students," Library \& Information Science Research 18 (spring 1996): 151-63.

82. Rothblum, Solomon, and Murakami, "Affective, Cognitive, and Behavioral Differences between High and Low Procrastinators."

83. Solomon and Rothblum, "Academic Procrastination."

84. Esther D. Rothblum, Gery Beswick, and Leon L. Mann, "Psychological Antecedents of Student Procrastination" (unpublished manuscript, Flinders Univ. of South Australia, Adelaide, 1984).

85. Kuhlthau, "Developing a Model of the Library Search Process."

86. —— "Inside the Search Process."

87. Leon Green, "Minority Students' Self-Control of Procrastination," Journal of Counseling Psychology 29 (Nov. 1982): 636-44.

88. Steven C. Richards, "Behavior Modification of Studying through Study-Skills Advice and Self-Control Procedures," Journal of Counseling Psychology 22, no. 5 (Sept. 1975): 431-36.

89. Harold A. Ziesar, Ted L. Rosenthal, and Glenn M. White, "Behavioral Self-Control in Treating Procrastination of Studying," Psychological Reports 42, no. 1 (Feb. 1978): 56-69.

90. Gregg Mulry, Raymond Fleming, and Ann C. Gottschalk, "Psychological Reactance and Brief Treatment of Academic Procrastination," Journal of College Student Psychotherapy 9, no. 1 (spring 1994): 41-56.

91. Thomas E. Dowd, Shari L. Hughes, Linda Brockbank, and Dale Halpain, "Compliancebased and Defiance-based Intervention Strategies and Psychological Reactance in the Treatment of Free and Unfree Behavior," Journal of Counseling Psychology 35, no. 4 (Oct. 1988): 370-76.

92. Thomas E. Dowd and Joseph S. Swoboda, "Paradoxical Interventions in Behavior Therapy," Journal of Behavior Therapy and Experimental Psychiatry 15, no. 3 (Sept. 1984): 229-34.

93. Michael Rohrbaugh, Howard Tennen, Samuel Press, and Larry White, "Compliance, Defiance, and Therapeutic Paradox," American Journal of Orthopsychiatry 51, no. 3 (July 1981): 454-67.

94. Rothblum, Solomon, and Murakami, "Affective, Cognitive, and Behavioral Differences between High and Low Procrastinators." 